\title{
Contaminated land, ecological assessment, and remediation conference series (CLEAR 2012): environmental pollution and risk assessments
}

\author{
Ming-Hung Wong • Barry Noller • Ravi Naidu • \\ Thomas Baumgartl
}

Received: 20 September 2013 / Accepted: 24 September 2013 /Published online: 31 October 2013

(C) Springer-Verlag Berlin Heidelberg 2013

Population growth, urbanization, and industrialization have contributed to the emission of a wide array of pollutants into different ecological compartments (air, water, and soil). Environmental pollution has been largely acknowledged and addressed by industrialized countries in the past; however, for developing countries such as China, the issue of environmental degradation and accompanying health problems is a timely topic as they are undergoing socioeconomic and industrial development with a pace and scale greater than previously industrialized countries. With less stringent environmental regulations and lack of public concern, environmental degradation (affecting air, water, and land) and accompanying health problems have become a growing concern in developing nations. In particular,

Responsible editor: Philippe Garrigues

M.-H. Wong

School of Environmental and Resource Sciences, Zhejiang

Agricultural and Forestry University, Linan, People's Republic of China

M.-H. Wong $(\bowtie)$

Croucher Institute for Environmental Sciences, Hong Kong Baptist

University, Hong Kong SAR, People's Republic of China

e-mail: mhwong@hkbu.edu.hk

B. Noller · T. Baumgartl

Centre for Mined Land Rehabilitation, The University of

Queensland, Brisbane, Australia

R. Naidu

Centre for Environmental Risk Assessment and Remediation (CERAR), Building X, University of South Australia, University

Boulevard, Mawson Lakes, SA 5095, Australia

R. Naidu

CRC for Contamination Assessment and Remediation of the Environment (CRC CARE), Building X, University of South

Australia, Mawson Lakes, SA 5095, Australia land contamination poses a serious threat to the environmental quality, food production, and food safety in these regions.

Contaminated Land, Ecological Assessment, and Remediation Conference (CLEAR) is a new conference series which provides a platform for interaction between scientists, consultants, and policy makers, who are responsible for improving our environment in order to cope with the rapid industrial development. The first of the conference series was held in Hangzhou, Zhejiang Province, China, November 4-8, 2012. The Zhejiang Province has one of the highest agricultural outputs in China; thus, it is highly fitting to explore the issue of land contamination and food and health safety in Hangzhou, the largest and capital city of this province.

This special issue of ESPR is a collection of selected contributions that is published after a stringent peer-reviewed process from the CLEAR 2012 conference participants, highlighting the current scientific knowledge on environmental pollution, risk assessment, and potential remediation strategies on land contamination in China and other developing nations, such as Mexico. Accordingly, the special issue is structured into three sections with papers presented in the following order: environmental pollution, risk assessments, and remediation. The first section, environmental pollution, covers a wide range of contaminants found in soil and sediments of varying land use due to anthropogenic activities, including heavy metals (arsenic, mercury, etc.), industrial solvents like trichloroethylene, agricultural fertilizers such as phosphorous, and pharmaceutical residues, a type of pollution that has received increasing public concern. In the second section, risk assessment of various contaminants are detailed, such as heavy metals in mining soil and its risks on inhabitants, environmental assessment of a lead-contaminated shooting range, and assessing PAHs and OCPs levels in endangered bird species using a noninvasive method. Lastly, the third section, remediation, focuses on the use of biochar for remediation of contaminated 
land, as well as controlling phosphorous in a eutrophied lake and intercropping of plants and its relation to arbuscular mycorrhizal fungi and $\mathrm{Cd}$ and $\mathrm{P}$ phytoavailability.

The 3-day conference with 150 participants, including 45 overseas participants from over 20 countries, has yielded many fruitful discussions and information exchange related to land contamination, risk assessment, and remediation that has given rise to this special issue. To this end, we would like to thank the conference organizing committee and sponsorships from Zhejiang Agricultural and Forestry University, Cooperative Research Center - Contamination and Assessment of the Environment, Australia, Institute of Soil Science as well as the Directors of the three Environmental Engineering Companies (Beijing Dingshi, Zhejiang Shangda, and Zhongke Huanan) for their generous support. Our sincere thanks go to authors and reviewers for their hard work and contribution and to Dr. Philippe Garrigues, the editor-in-chief, for the kind invitation to publish this special issue.

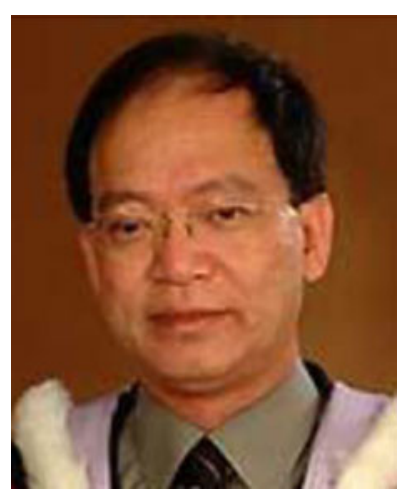

Ming-Hung Wong BS c (CUHK); MSc, PhD, DSc (Durham); MBA, DSc (Strathclyde) is chair professor of biology and honorary director of the Croucher Institute for Environmental Sciences at Hong Kong Baptist University. His major research areas include ecotoxicological assessment and remediation of sites contaminated with toxic metals and persistent organic pollutants, and bioconversion of waste. He has been awarded a DSc each from the University of Durham and the University of Strathclyde based on papers published during the period 1977-1990 and 1991-2002, respectively. Professor Wong served as the regional coordinator of Central and North-East Asia for the project entitled "Regionally Based Assessment of Persistent Toxic Substances" and recently joined a panel of three to review "Emerging Chemicals Management Issues in Developing Countries and Countries with Economies in Transition," which was sponsored by the United Nations Environment Programme (UNEP) and the Global Environment Facility (GEF). Currently, he is editor in chief of Environmental Geochemistry and Health (Springer) and editorial board member of five other international scientific journals.

Professor Wong has published over 530 peer-reviewed papers and 24 book chapters and has served as the editor of 22 books/special issues of scientific journals. He is currently the most cited Chinese scientist in the world in the field of environment/ecology, according to the Web of Science.

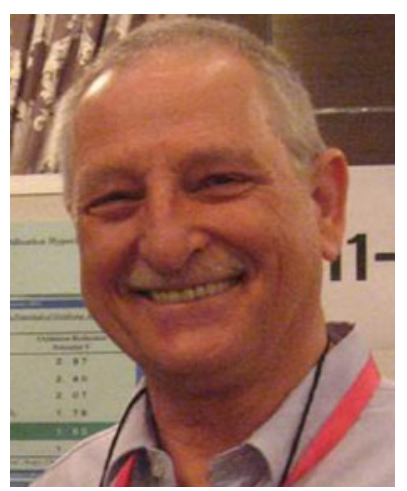

Barry Noller is Principal Research Fellow at the Centre for Mined Land Rehabilitation, The University of Queensland. He received his Ph.D. 1978 in environmental chemistry from the University of Tasmania and was appointed Research Fellow Australian National University 1978, Research Scientist Environmental Research Institute of the Supervising Scientist, Jabiru, Northern Territory 1980, Principal Environmental Chemist for the Department of Mines and Energy, Darwin, 1990 and Deputy Director of the National Research Centre for Environmental Toxicology (ENTOX) at The University of Queensland 1998 - 2006. He has worked in the field of environmental chemistry and industrial toxicology for the past 40 years and has authored $>175$ peer reviewed papers and conference proceedings and $>370$ conference papers covering processes and fates of trace substances in tropical environmental systems, bioavailability of toxic elements in mine wastes, studies of arsenic and metal speciation of solid mine waste materials using synchrotron induced X-ray analysis and developed speciation-based toxicity models for mine closure purposes.

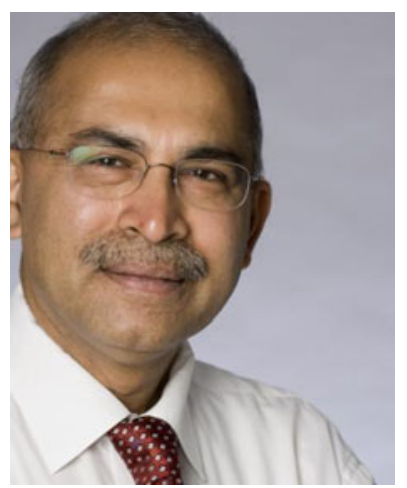

Ravi Naidu is the Managing Director of the Cooperative Research Centre for Contamination Assessment and Remediation of the Environment (CRC CARE) and the inaugural Director of the Australian Research Centre for Environmental Risk Assessment and Remediation. Prof. Naidu is an expert in environmental contaminants, toxicology, bioavailability and remediation. He has co-authored over 500 technical publications and co-edited 10 books in the field of soil and environmental sciences, including field remediation of contaminated sites.

In 2013 Prof. Naidu was elected as Fellow of the American Association for the Advancement of Science, and in 2012 won the Soil Science Society of America (SSSA) International Soil Science Award. Other awards conferred on Prof. Naidu include: Fellow of Agronomy Society of America (2006); Fellow of the Soil Science Society of New Zealand (2004); Fellow of the Soil Science Society of America (2000); and a Tamil Nadu Agricultural University's gold medal in environmental science (1998).

Prof. Naidu is currently Chair of the International Committee on Bioavailability and Risk Assessment. He has also been Chair of the International Union of Soil Sciences Commission for Soil Degradation Control, Remediation and Reclamation (2002-10) and President of the International Society on Trace Element Biogeochemistry (2005-07). 


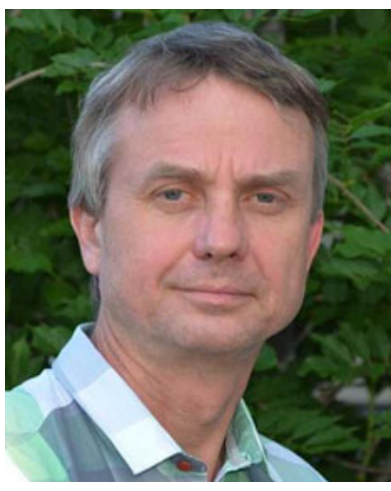

Thomas Baumgartl is Senior Research Fellow and Deputy Director at the Centre for Mined Land Rehabilitation, The University of Queensland. He received his Ph.D. 1991 in soil physics from the University of Bayreuth, Germany and habilitated in 2001 at the University of Kiel, Germany in the area of Soil Science. He was awarded a scholarship in 1995 by the Alexander-von-Humboldt Foundation and was visiting scientist at the University of Queensland in that year. In 2004, he joined the Centre for Mined Land Rehabilitation, The University of Queensland. He has worked in the field of environmental soil science in the past 30 years and has authored $>90$ peer reviewed papers and conference proceedings and has $>80$ conference contributions in the field of environmental soil science covering the areas of water flow in the soil-plant-atmosphere continuum, investigation of the mobilisation of salts and contaminants as part of hydrogeochemical process understanding and maximizing protection of the environment by the appropriate design of covers for waste material for the purpose of planning for mine closure. 